\title{
Climate variability of the mid- and high-latitudes of the Southern Hemisphere in ensemble simulations from 1500 to $2000 \mathrm{AD}$
}

\author{
S. B. Wilmes ${ }^{1,2, *}$, C. C. Raible ${ }^{1,2}$, and T. F. Stocker ${ }^{1,2}$ \\ ${ }^{1}$ Climate and Environmental Physics, University of Bern, Bern, Switzerland \\ ${ }^{2}$ Oeschger Centre for Climate Change Research, Bern, Switzerland \\ *now at: School of Ocean Sciences, Bangor University, Menai Bridge, UK
}

Correspondence to: S. B. Wilmes (wilmes@climate.unibe.ch)

Received: 1 September 2011 - Published in Clim. Past Discuss.: 4 October 2011

Revised: 13 January 2012 - Accepted: 16 January 2012 - Published: 29 February 2012

\begin{abstract}
To increase the sparse knowledge of long-term Southern Hemisphere (SH) climate variability, we assess an ensemble of 4 transient simulations over the last $500 \mathrm{yr}$ performed with a state-of-the-art atmosphere ocean general circulation model. The model is forced with reconstructions of solar irradiance, greenhouse gas (GHG) and volcanic aerosol concentrations. A 1990 control simulation shows that the model is able to represent the Southern Annular Mode (SAM), and to some extent the South Pacific Dipole (SPD) and the Zonal Wave 3 (ZW3). During the past $500 \mathrm{yr}$ we find that SPD and ZW3 variability remain stable, whereas SAM shows a significant shift towards its positive state during the 20th century. Regional temperatures over South America are strongly influenced by changing both GHG concentrations and volcanic eruptions, whereas precipitation shows no significant response to the varying external forcing. For temperature this stands in contrast to proxy records, suggesting that SH climate is dominated by internal variability rather than external forcing. The underlying dynamics of the temperature changes generally point to a combination of several modes, thus, hampering the possibilities of regional reconstructing the modes from proxy records. The linear imprint of the external forcing is as expected, i.e. a warming for increase in the combined solar and GHG forcing and a cooling after volcanic eruptions. Dynamically, only the increase in SAM with increased combined forcing is simulated.
\end{abstract}

\section{Introduction}

Present-day climate in the mid- and high-latitudes of South America is characterized by a high diversity of weather and climate patterns due to the considerable meridional extent of the landmass. The variability of the climate in this area on interannual to interdecadal scales is not only a result of distinct topographic features such as the Andes Cordillera, or the large water masses of the Southern Ocean, but also of a superposition of various tropical, subtropical and extratropical atmospheric variability patterns (Garreaud et al., 2009; Kidson, 1999) such as the Southern Annular Mode (SAM) (Thompson and Wallace, 2000), South Pacific Dipole (SPD) (Kiladis and Mo, 1998; Mo, 2000) and the Zonal Wave 3 (ZW3) (Raphael, 2004).

Little, however, is known about climatic changes in the Southern Hemisphere $(\mathrm{SH})$ during the last millennium in comparison to the Northern Hemisphere $(\mathrm{NH})$ due to the low density of proxy records in this area (Villalba et al., 2009). Nevertheless, the few available records point towards significant fluctuations in both temperature and precipitation occurring during this time period (Jones and Mann, 2004; Masiokas et al., 2009; Tonello et al., 2009). On this time scale orbital boundary conditions only changed slightly and thus internal variability, solar and volcanic forcing played a dominant role before the influence of humans became noticeable (Jones and Mann, 2004). Thus, this period provides the opportunity of placing the recent global climatic change into a longer term context and evaluating the impact of both the anthropogenic external forcing (increase in human-generated greenhouse gasses (GHG) and aerosol mass concentrations) and the natural external forcing (variations in insolation and volcanic eruptions). Recently, a first attempt to reconstruct patterns for southern South America by Neukom et al. (2011, 2010) points to a number of climatic variations occurring during this time period.

Besides the climate proxy records/reconstructions, simulations of the past using coupled climate models provide a good opportunity for exploring these variations and distinguishing between the impacts of the external forcing and changes 
Table 1. Overview of the simulations used in this study.

\begin{tabular}{lllcc}
\hline Model & Experiment & Forcing & Ensemble members & Model years \\
\hline CCSM3 & Ctr11990 & perpetual 1990 conditions & 1 & $480 \mathrm{yr}$ \\
CCSM3 & Ctr11500 & perpetual 1500 conditions & 1 & $652 \mathrm{yr}$ \\
CCSM3 & TR1a-TR4a & $\begin{array}{l}\text { transient forcing (see Fig. 1) } \\
\text { 1500-2000 }\end{array}$ & 4 & $500 \mathrm{yr}$ \\
\hline
\end{tabular}

in internal variability and links between the two (Yoshimori et al., 2005; Raible et al., 2006; Gonzalez-Rouco et al., 2011; Luterbacher et al., 2011).

In this context, the purpose of our study is to investigate mid- and high-latitudes changes in the atmospheric circulation over the SH, in particular South America. Atmospheric changes also show feedbacks to the ocean circulation and sea ice distribution and hence exceed at least regional importance (Lefebvre et al., 2004; Biastoch et al., 2009). Understanding past changes in climatic patterns and the dynamics behind them is key to assessing the possible changes taking place in the future (Jansen et al., 2007) and providing high quality advice to societies for mitigation.

This study is based on an ensemble of 4 transient simulations over the last $500 \mathrm{yr}$ from an atmosphere ocean general circulation model, i.e. the Climate Community System Model (Version 3; CCSM3). In a first step, the model's ability to simulate present day Southern Hemisphere climate is presented by comparing a control simulation with constant forcing at $1990 \mathrm{AD}$ levels to reanalysis data from the ECMWF (ERA-40). Then, the Southern Hemispheric climate variations of the past half millennium are investigated using the ensemble simulations. Thereby, changes in the leading atmospheric modes of internal climate variability the SAM, the SPD and the ZW3 - are presented; it is investigated how temperature and precipitation in specific, proxy covered areas of South America are linked to the large-scale atmospheric circulation by a bottom up approach and we investigate which areas of the mid- and high-latitudes in the Southern Hemisphere are most sensitive to external forcing. The focus shall lie on temperature and moisture changes, as these are the variables most strongly affecting both ecosystems and human societies (Parry et al., 2007) and have the potential to be registered in various proxy archives.

\section{Data, model, and experimental design}

Using the low resolution (T31x3) version of the fully coupled Community Climate System Model Version 3.0.1 (CCSM3), which was developed at the National Centre for Atmospheric Research (NCAR) (http://www.ccsm.ucar.edu/models), two types of simulations were performed for this and further studies (Yoshimori et al., 2010; Hofer et al., 2011): equilibrium or control simulations with constant external forcing and transient runs with time varying forcing. The equilibrium simulations are used to provide the initial conditions for the transient simulations and to generate a reference state for a stable climate, whereas the transient simulations serve to evaluate the effects and feedbacks of variations in the external forcing on the climate system. For the subsequent analysis only monthly averaged data are considered. An overview of all experiments conducted is given in Table 1. A detailed description and evaluation of the model can be found in Collins et al. (2006) and Yeager et al. (2006).

Two control experiments were integrated for this study: one integration with constant external forcing corresponding to levels at $1990 \mathrm{AD}$ (CTRL1990) to evaluate the model performance for present day climate (a detailed analysis of the 1990 CTRL was carried out by Yeager et al., 2006), and a simulation with external forcing at $1500 \mathrm{AD}$ levels. For the CTRL1990, the 1990 AD control simulation performed by the NCAR was extended by several decades. The CTRL1500 run was branched from the extended CTRL1990 simulation. In order to allow for adjustments to the changes in the external forcing, the first $50 \mathrm{yr}$ of the CTRL1500 simulations are not used for analysis. Nevertheless, the simulation still shows a drift towards a colder climate which corresponds to an approximately linear trend in the atmosphere and at the sea surface and exhibits a decrease in strength over time in the deep ocean (Hofer et al., 2011). In order to minimize the effect of such artificial trends, all variables are detrended using a least-squares quadratic fit (see Hofer et al., 2011, for more details).

In addition to the perpetual CTRL1990 and CTRL1500 simulations, an ensemble of four transient simulations (TR01 to TR04) with time varying forcing from $1500 \mathrm{AD}$ to $2100 \mathrm{AD}$ was conducted. The simulations were branched from different starting years within CTRL1500 to give different initial conditions at $1500 \mathrm{AD}$ for the TR simulations. They are driven with reconstructions of the natural forcing, which consists of solar irradiance variations, volcanic eruptions and GHGs for $1500 \mathrm{AD}$ to $2000 \mathrm{AD}$. A detailed description of the experimental setup and the external forcing is given in Yoshimori et al. (2010) and Hofer et al. (2011). The main natural and anthropogenic forcings are summarized in Fig. 1. The transient simulations were detrended prior to analysis using the same procedure as for the control simulation in order to minimize the effect of the drift in the simulations, which is mainly due to the long adjustment time of 


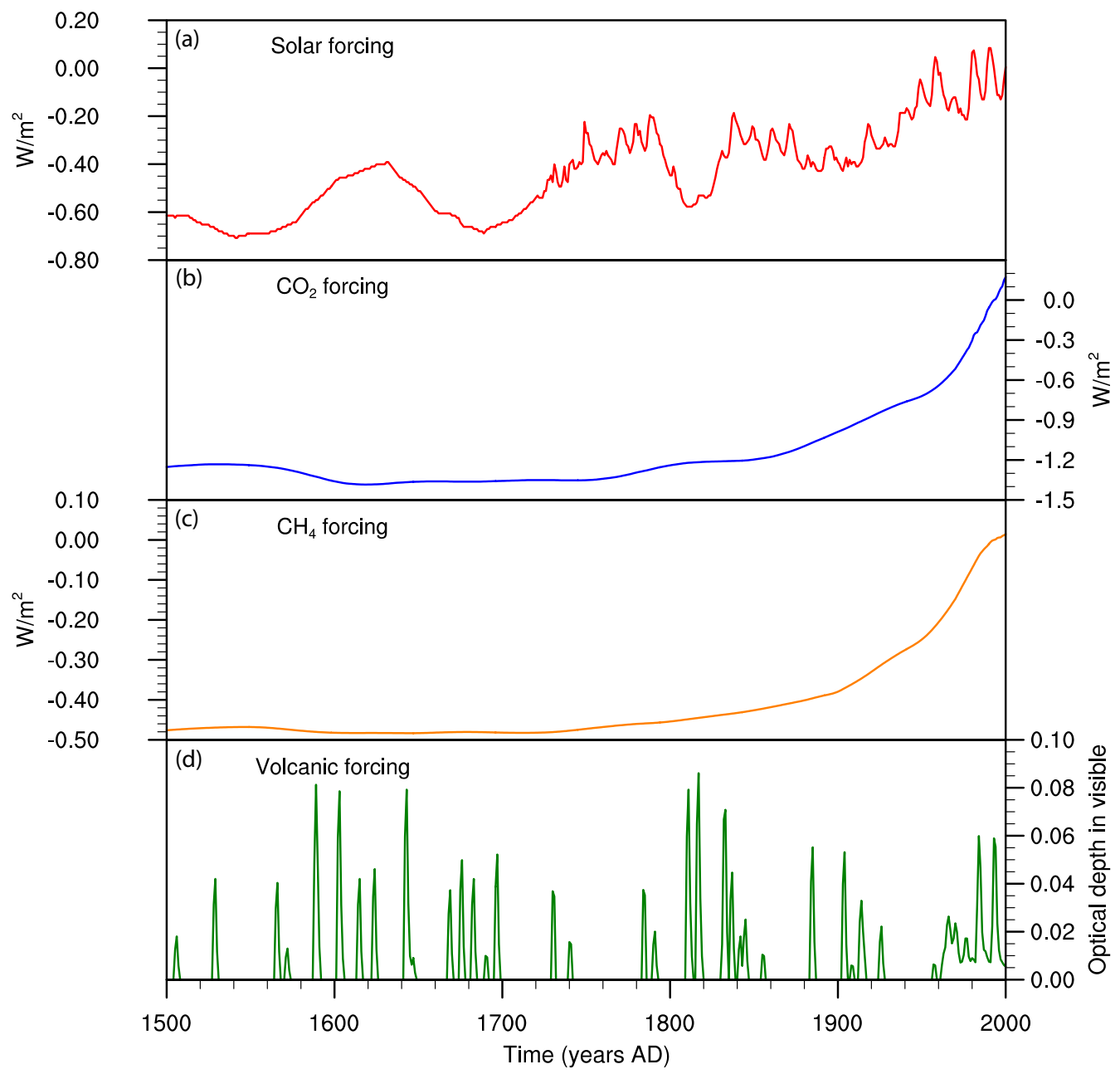

Fig. 1. Natural and anthropogenic forcing and optical depth from $1500 \mathrm{AD}$ to $2000 \mathrm{AD}$ used for the transient simulations. (a) Solar irradiance changes according to Crowley (2000) scaled to the Lean et al. (1995) reconstruction, (b) $\mathrm{CO}_{2}$ variations reconstructed by Etheridge et al. (1996), (c) $\mathrm{CH}_{4}$ forcing anomalies based on $\mathrm{CH}_{4}$ concentrations reconstructed by Blunier et al. (1995) and , and (d) volcanic forcing shown as variations in optical depth (Crowley, 2000, scaled to Ammann and Naveau, 2003).

the deep ocean. This procedure is similar to the one applied by, e.g. Ammann et al. (2007).

\subsection{Observational data}

In order to evaluate the performance of the model for present-day climate, we use the monthly means of the ERA-40 reanalysis data (Uppala et al., 2005). These data are interpolated to a resolution of $2.5^{\circ} \times 2.5^{\circ}$ in latitude and longitude and are available for 23 pressure levels throughout the atmosphere $(1000 \mathrm{hPa}$ to $1 \mathrm{hPa})$ on the ECMWF website (http://www.ecmwf.int/products/data/ archive/descriptions/e4/index.html).

\section{Model evaluation}

In this section the ability of CCSM3 to represent the presentday atmospheric variability modes of the mid- and highlatitudes of the Southern Hemisphere is evaluated. For this, the CTRL1990 simulation is compared to reanalysis data from the ECMWF ERA-40 project. The El Niño Southern Oscillation (ENSO) shall not be touched on as it has previously been evaluated by Yeager et al. (2006) and Collins et al. (2006). They find that CCSM3 simulates a qualitatively realistic ENSO pattern which, however, occurs too regularly and at higher frequencies than observed.

\subsection{Southern annular mode}

SAM is calculated as the leading empirical orthogonal function (EOF) of the geopotential height field at $850 \mathrm{hPa}$ (Z850) 

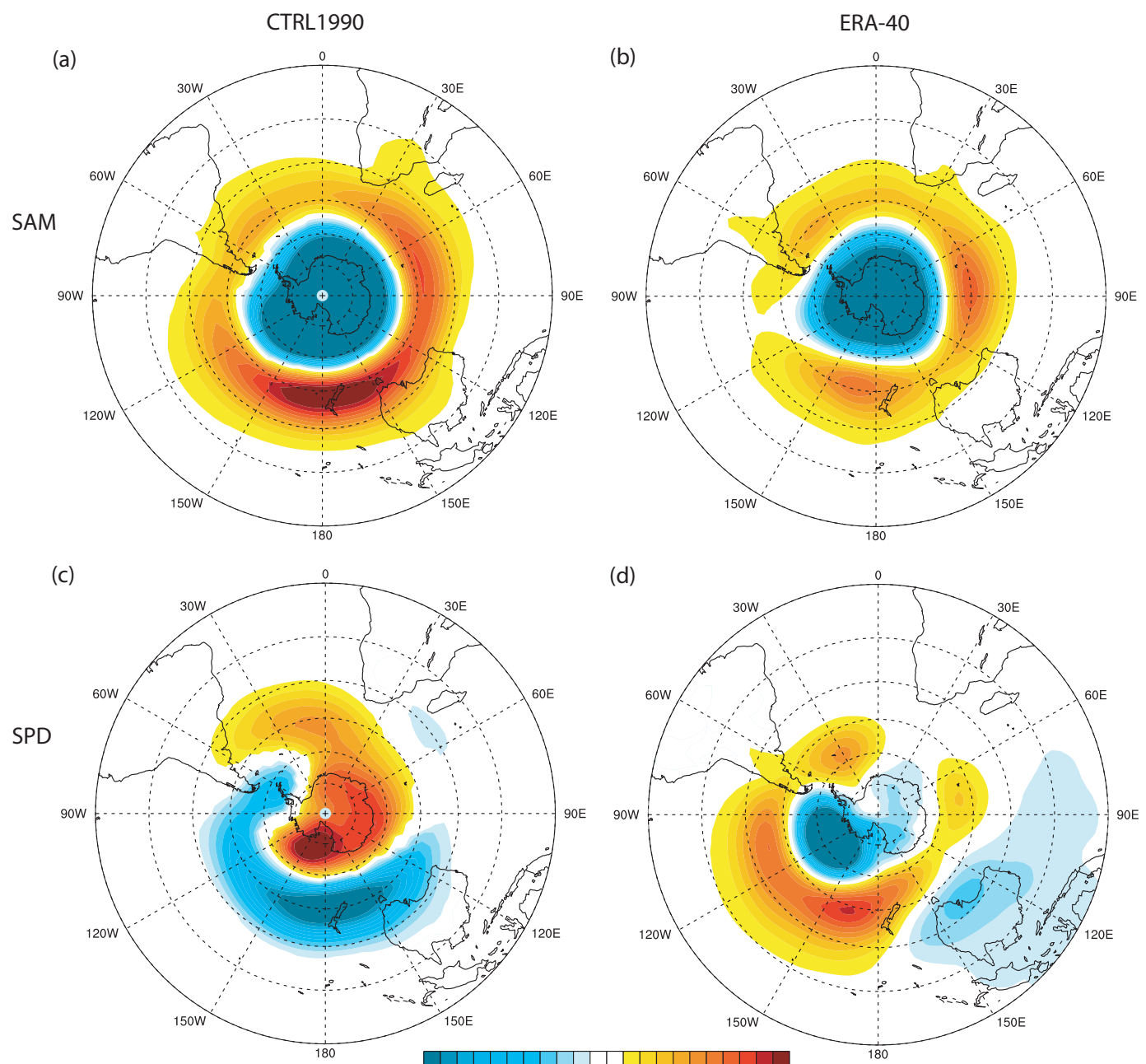

(d)
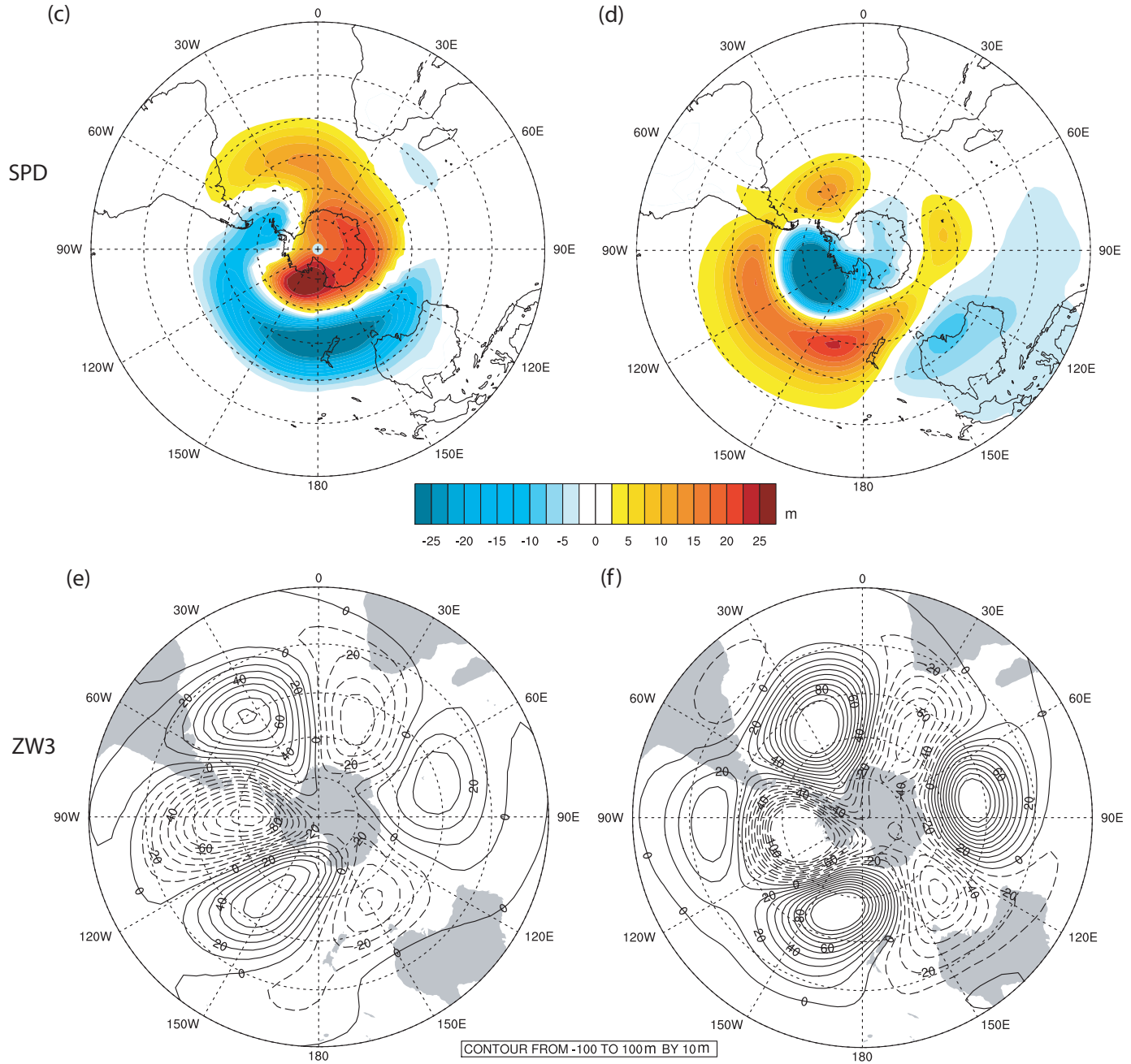

Fig. 2. Spatial patterns of (a) the SAM for the CTRL1990 simulation and (b) for ERA-40 reanalysis data; (c) the SPD for the CTRL1990 simulation and (d) for ERA-40 reanalysis; (e) the ZW3 for the CTRL1990 simulation and (f) for ERA-40 reanalysis. (a) to (d) are shown as a regression of the time series of the respective mode onto the $\mathrm{Z} 850 \mathrm{hPa}$ field. Units are $\mathrm{m}$ per standard deviation change of the index. Only values significant at the $5 \%$ level have been coloured. (e) and (f) show the composite of the spatial anomalies of \pm 1 standard deviations of the ZW3 index. 

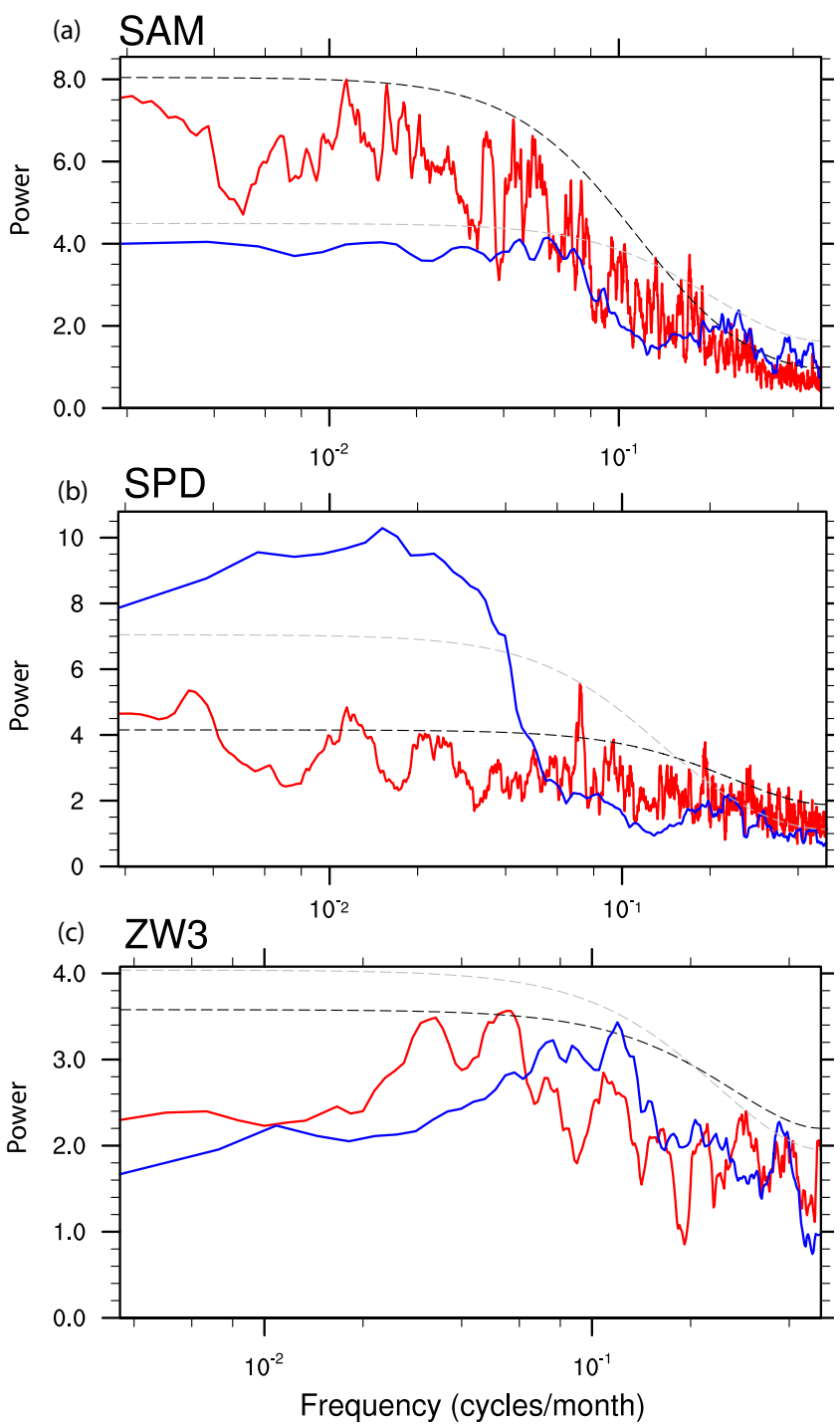

Fig. 3. Spectra of the monthly (a) SAM index, (b) SPD index and (c) ZW3 index calculated for both the CTRL1990 simulation (red) and for ERA-40 reanalysis data (blue). The dashed lines indicate the $95 \%$ confidence levels based on a Markow red noise spectrum with the same variance for the CTLR1990 simulation (black) and the ERA-40 data (gray).

south of $20^{\circ} \mathrm{S}$ after removing the seasonal cycle and applying area weighting according to Thompson and Wallace (2000). As the comparison between this method and the one proposed by Gong and Wang (1999) yields a highly significant correlation of $r=0.83$ between the modeled indices, the analysis is restricted to the EOF-method.

Figure $2 \mathrm{a}$ and $\mathrm{b}$ show the SAM patterns calculated for CTLR1990 and ERA-40, respectively. The patterns correspond well with a pattern correlation of $r=0.89$. The model shows a slightly more zonal structure than expected from ERA-40 where three distinct centers of action are visible.
Also, CCSM3 overestimates the variability explained by SAM: whereas SAM accounts for $17 \%$ of the variance in the observed Z850 field, it explains $28 \%$ in CTRL1990. Spectra calculated for both CTRL1990 and ERA-40 (Fig. 3a) show that for time scales greater than $2 \mathrm{yr}$, SAM essentially represents a white-noise process. At higher frequencies, ERA-40 shows a significant peak at approximately 5 months and the CTRL1990 at 6 months. However, for longer time scales the CCSM3 overestimates the variability explained by SAM.

\subsection{South pacific dipole}

The SPD pattern calculated as the second EOF of the extra-tropical Z850 field is presented in Fig. 2c and d for CTLR1990 and ERA-40, respectively. For ERA-40, the wave train from the South Pacific into the South Atlantic is identified, whereas in the model this pattern is not as clearly expressed. Two centers of action of the simulated pattern lie to the east of New Zealand and over the BellingshausenAmundsen/Ross Sea, similar to the observations; the third is shifted south-east with respect to the expected pattern and connected to the first centre of action. The resulting pattern correlation yields a value of $r=0.36$, which is rather weak but still statistically significant at the $1 \%$ level. In ERA-40 this mode accounts for $10.4 \%$, in CTRL1990 the value is slightly lower with $7.0 \%$. Higher order EOFs of Z850hPa in the CTRL1990 simulations do not resemble the observed SPD pattern. The spectrum of the SPD index for ERA-40 (Fig. 3b) shows a band of significant variability between 2 and $20 \mathrm{yr}$ peaking at $8 \mathrm{yr}$. Similarly, peaks appear in CTRL1990; however, here the peaks are clearly separated and do not merge as for ERA-40. Moreover, the simulated variability of the SPD is less read than observed.

\subsection{Zonal Wave 3}

The ZW3 is defined as the first EOF of meridional wind speed at the $500 \mathrm{hPa}$ level (V500), as for SAM removing the seasonal cycle and applying area weighting. This method given by Yuan and $\mathrm{Li}$ (2008) yields similar results to the one proposed by Raphael (2004). In the CTRL1990, simulation EOF2 corresponds to the pattern found for EOF1 in ERA40 and will therefore subsequently be used to calculate the ZW3 in the model. The ZW3 patterns for both CTRL1990 and ERA-40 can be seen in Fig. $2 \mathrm{e}$ and $\mathrm{f}$. The variance explained by the patterns is very similar, with 11.8 and $9.7 \%$, respectively. The CTRL1990 shows a wave number 3 pattern very similar to ERA-40, which is backed up by a high pattern correlation of $r=0.71$. Spectra (Fig. 3c) estimated for the observed and the simulated indices suggest that, for time scales greater than one year, the ZW3 is predominantly a white noise process.

Therefore, we conclude that CCSM3 is generally able to represent the main spatial and temporal features of the midand high-latitude atmospheric modes well that, however, due 

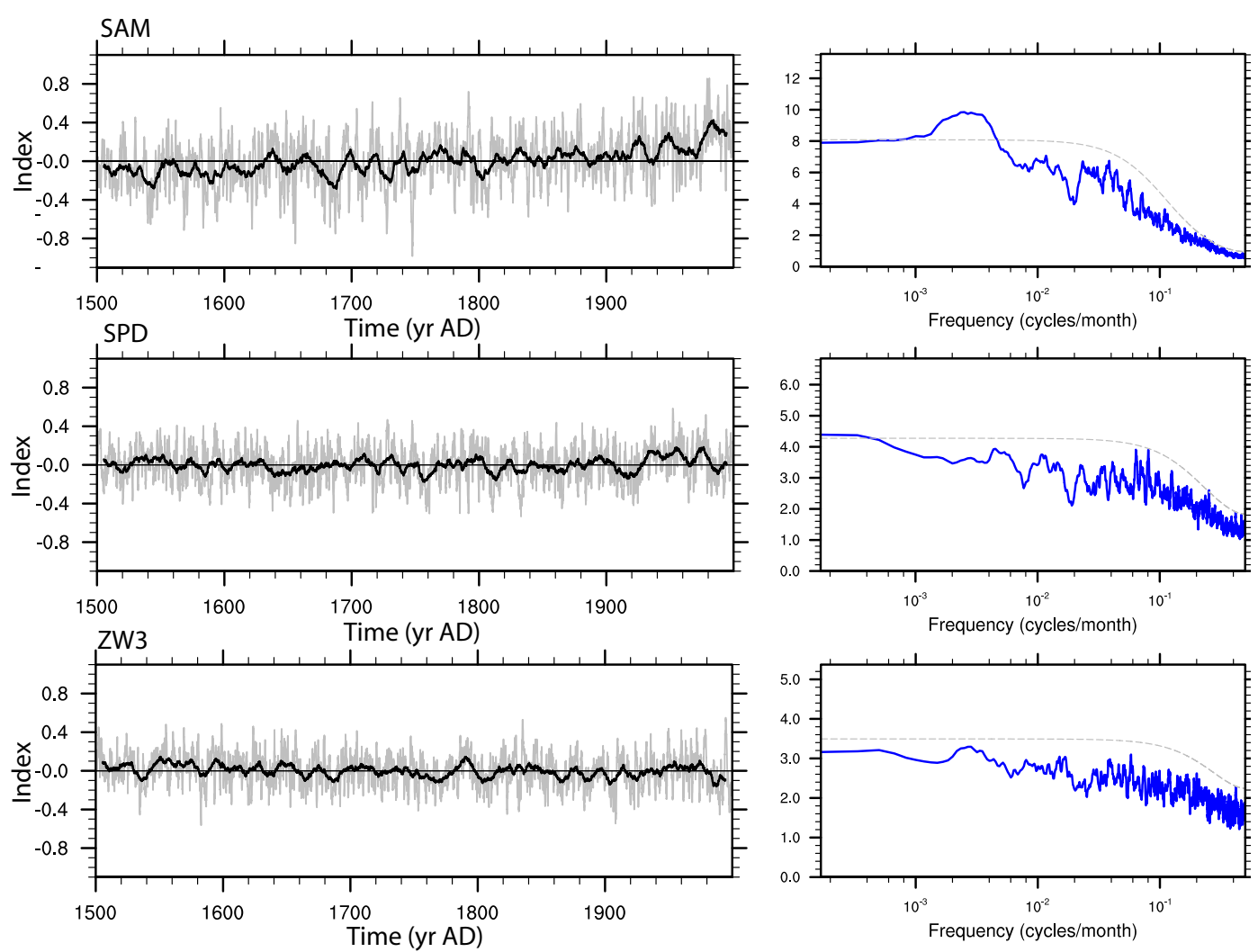

Fig. 4. Time series (black) of the monthly (a) SAM index, (b) SPD index and (c) ZW3 index calculated for transient simulations shown as the ensemble mean smoothed with a 12-month running mean (grey) and an $11 \times 12$-month running mean (black). The corresponding spectrum is shown on the right hand side (blue) with the dashed lines indicating the $95 \%$ confidence levels of the theoretical Markow red noise spectrum.

to the biases for both the SPD and the ZW3, these modes need to be treated with care when further analyzed.

\section{Climate variability from $1500 \mathrm{AD}$ to $2000 \mathrm{AD}$}

In Sect. 4.1, changes in the atmospheric modes in the transient simulations are analyzed, Sect. 4.2 discusses regional changes in temperature and precipitation in southern South America, Sect. 4.3 investigates the underlying dynamics of the temperature and precipitation variations in southern South America, and Sect. 4.4 investigates the effect of external forcings.

\subsection{Atmospheric modes}

Figure 4 shows the ensemble mean time series and the standard deviation of SAM, SPD and ZW3, respectively, which gives a first impression regarding the impact of the external forcing on these modes of variability. Additionally, the corresponding spectra are presented to investigate the preferred time scales of the modes.

During the 16th century the ensemble mean SAM index remains in a generally negative state. Neutral conditions are simulated between approximately $1650 \mathrm{AD}$ and $1800 \mathrm{AD}$.
Around 1700 and $1800 \mathrm{AD}$, pronounced shifts to SAMnegative conditions occur, both corresponding to strong volcanic eruptions. During the latter half of the 19th century and throughout the 20th century, a positive trend in SAM can be seen, which is significant at the $5 \%$ level. This corresponds to recent observations (Thompson and Wallace, 2000) and, as expected, is related to a strengthening of the mid latitude westerly winds. The spectrum of the ensemble members reveals a peak at approximately $40 \mathrm{yr}$, which was not present in the control simulation and the observations.

In contrast to SAM, no significant trends or large shifts can be seen for SPD and ZW3 indices; however, the SPD does appear to undergo slight shifts to more negative conditions during the two strong volcanic events at the beginning of the 19th century. Both spectra, as for CTRL1990, correspond to white-noise processes.

\subsection{Regional change in temperature and precipitation in southern South America}

In order to enable comparisons between the simulations and proxy records, and to evaluate the causes of regional climatic variations, four regions in southern South America (SA1 to SA4) were selected by first correlating the temperature and precipitation time series of single locations throughout 

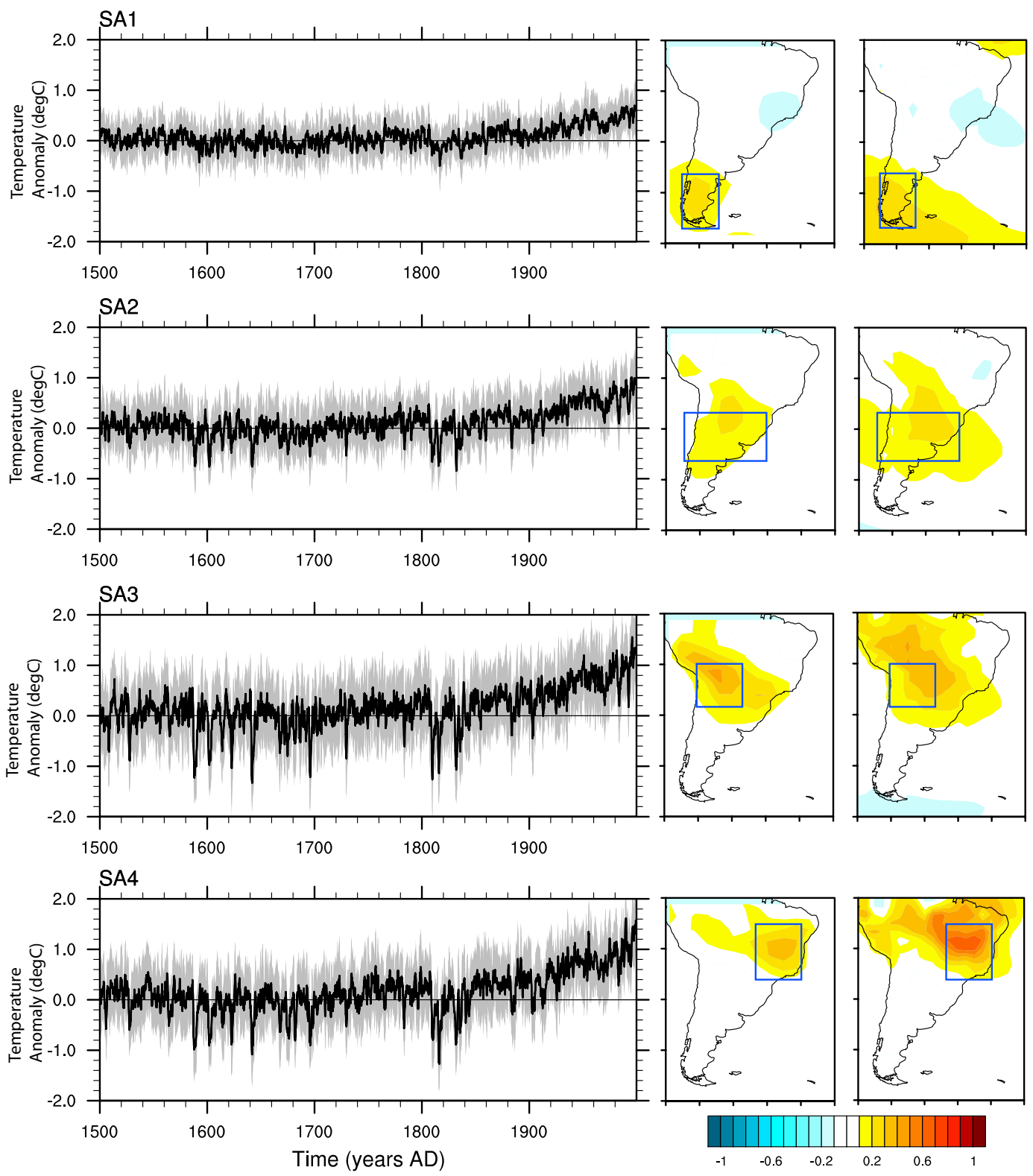

Fig. 5. Time series of the regional monthly temperature anomalies against the pre-industrial mean smoothed with a 12-month running mean for illustrative regions in South America. The ensemble mean is shown in black and the one standard deviation range in grey. The correlation pattern of the respective regional temperature index with the spatial temperature pattern together with the selected region (blue box) is shown for both CTRL1990 (left maps) and ERA-40 (right maps).

southern South America, and then the emerging patterns were grouped into four regions (SA1 to SA4) to maximize the covariability of each temperature and precipitation within the region. The regions and correlation patterns for both the CTRL1990 simulation and ERA-40 can be seen in the small insets in Figs. 5 and 6.

The regional temperature anomalies (Fig. 5) closely follow the external forcing signal, with especially the volcanic and GHG forcing showing pronounced temperature responses which are most notable in the two most northerly regions
(SA3 and SA4), whereas the impact in Patagonia (SA1) appears weakest.

Precipitation variations (Fig. 6) in contrast are marked by a high degree of internal variability. No significant shifts or trends appear in either of the regions throughout the course of the simulations and no significant relationship between the external forcing and precipitation variations can be detected. 

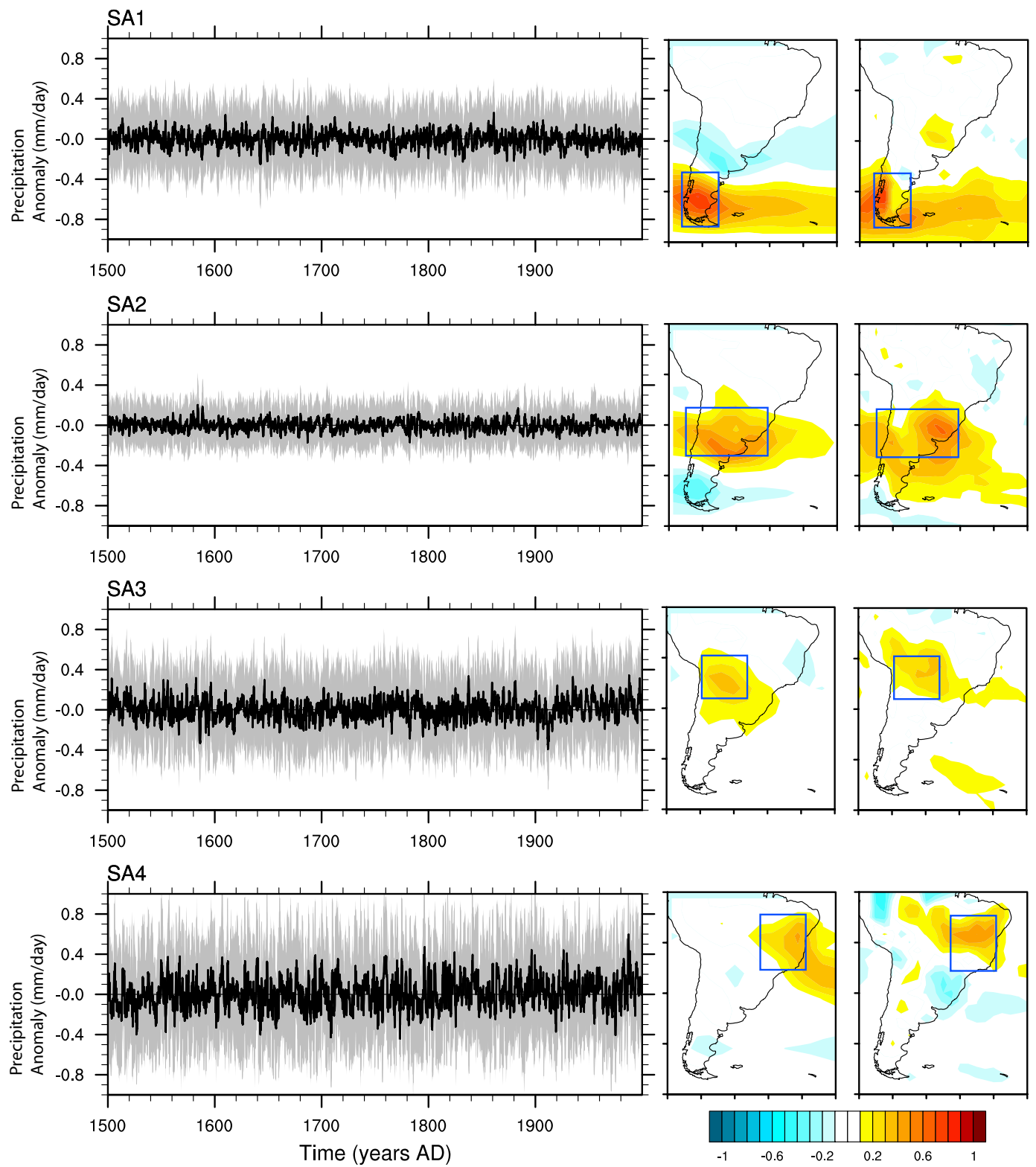

Fig. 6. Time series of the regional monthly precipitation anomalies against the pre-industrial mean smoothed with a 12-month running mean for illustrative regions in South America. The ensemble mean is shown in black and the one standard deviation range in grey. The correlation pattern of the respective regional precipitation index with the spatial precipitation pattern together with the selected region (blue box) is shown for both CTRL1990 (left maps) and ERA-40 (right maps).

\subsection{Underlying dynamics}

When reconstructing atmospheric modes from regional proxy records, it is crucial that the variations in the record only reflect changes in the mode and not a combination of processes. Therefore, we take a bottom-up approach and assess the underlying dynamics of the temperature and precipitation changes. For this, a regression analysis between the normalized regional temperature and precipitation fields and the Z850 field is carried out. Figure 7 shows the emerging pattern for the ensemble average (the patterns for each TR simulation were calculated separately and then averaged).

The underlying dynamics of temperature variations in Patagonia (SA1) show that advection plays an important role in this area in causing temperature variations. Anomalous airflow from the north increases temperature, whereas colder air from the south leads to a decrease in temperature. The atmospheric dynamics reflect a combination of the SAM, SPD and ZW3 patterns, suggesting that a temperature record from this region does not simply represent a single mode. This is 


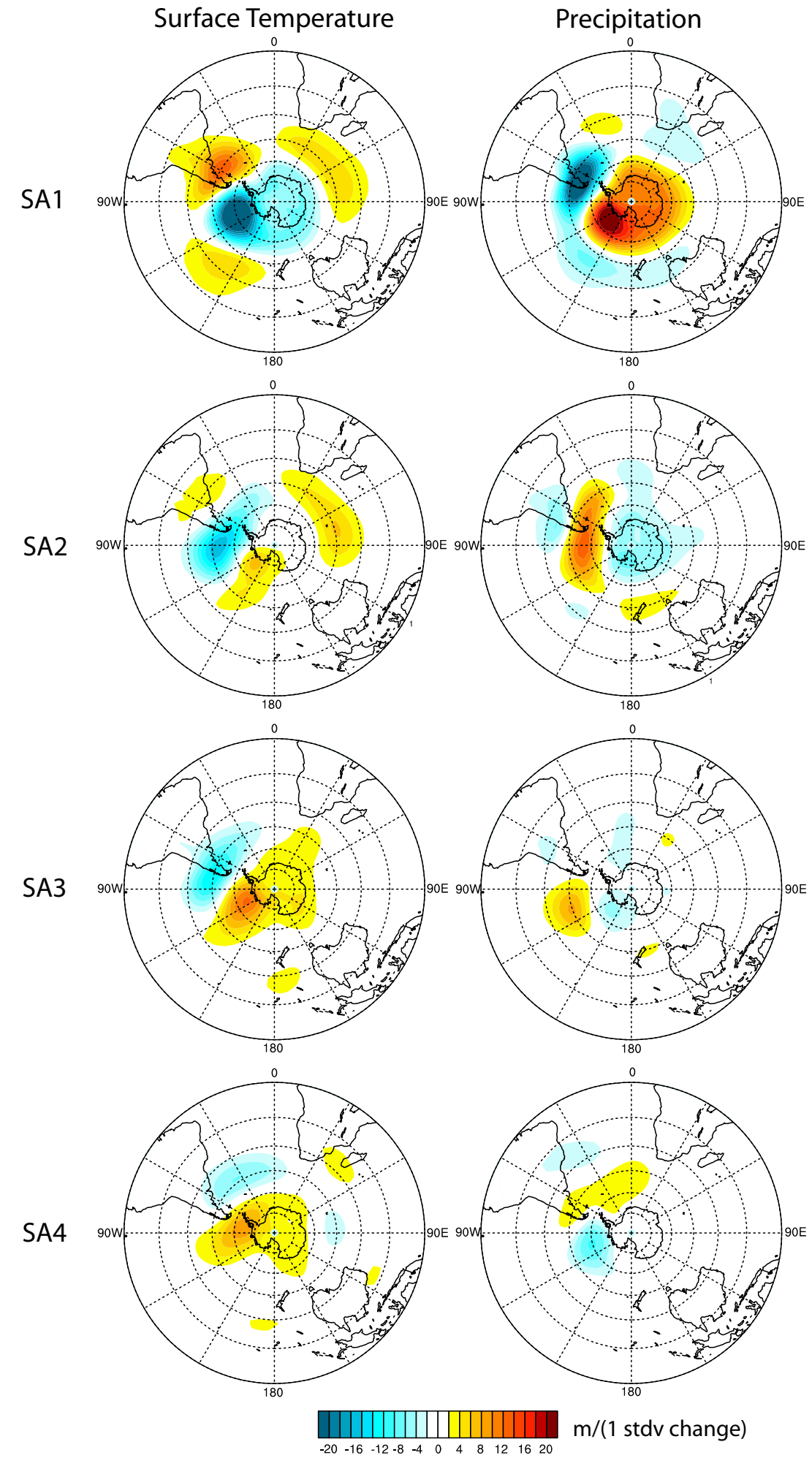

Fig. 7. Ensemble average regression coefficients between normalized regional surface temperature (left panel) and precipitation (right panel) anomalies and Z850. Units are $\mathrm{m}$ per one standard deviation change of temperature or precipitation, respectively. 


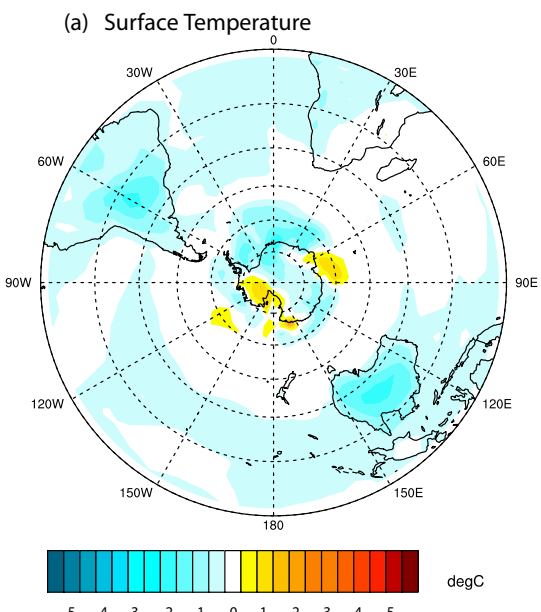

(c) Precipitation
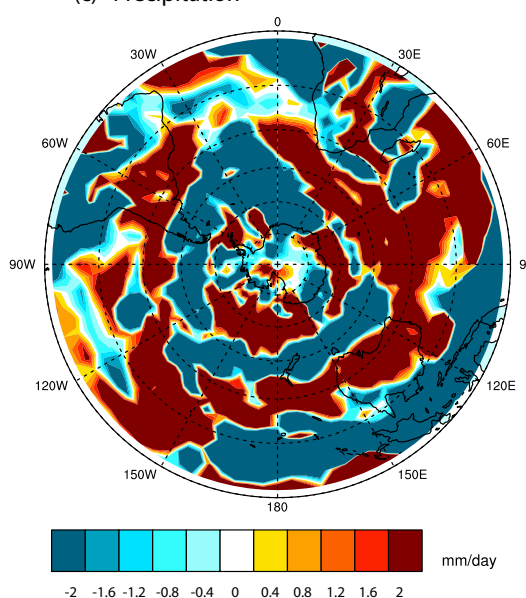

(e) Surface U-winds
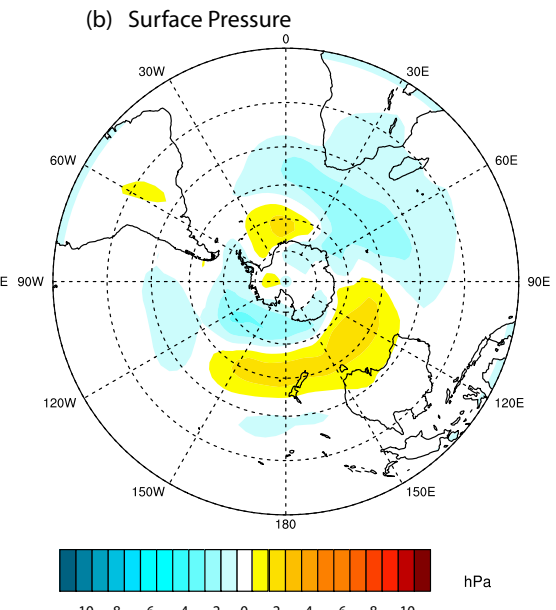

(d) Sea Surface Temperatures
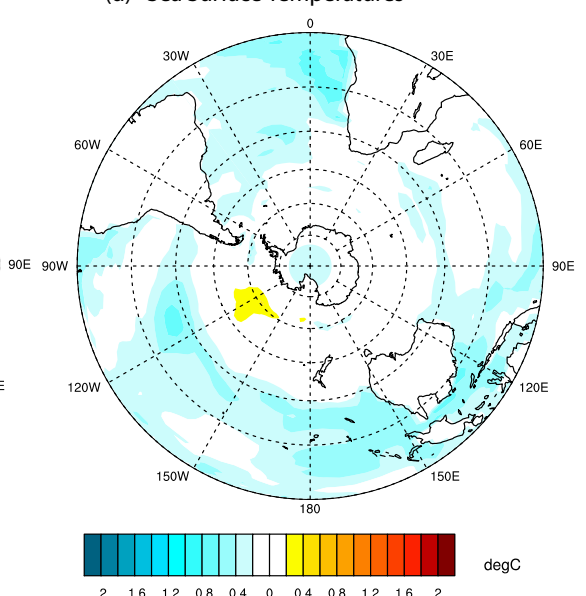

(f) Surface V-winds
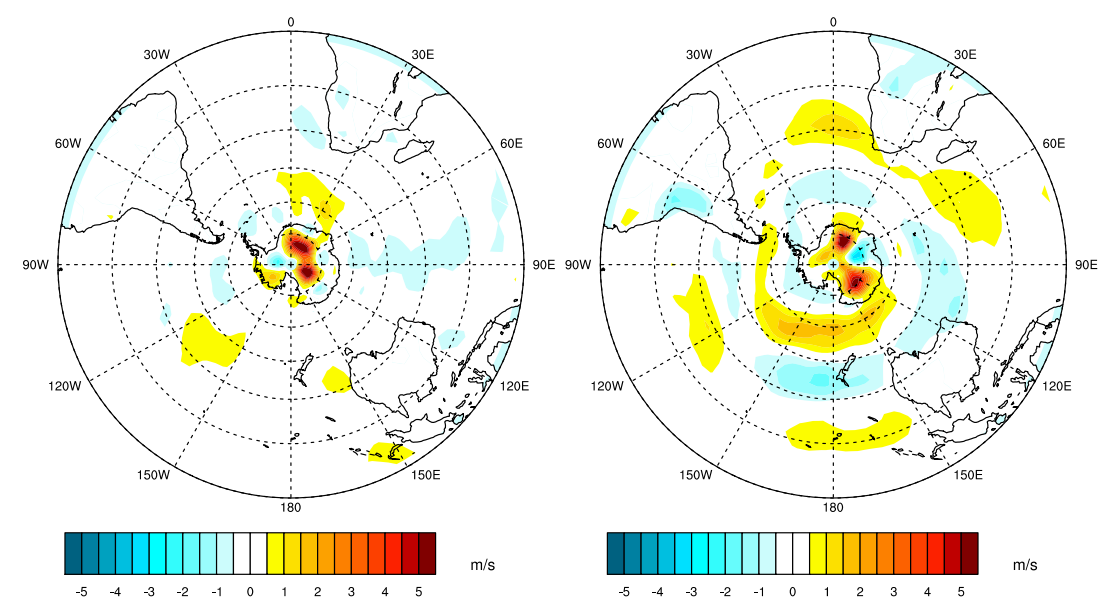

Fig. 8. Regression coefficients between the volcanic forcing and the changes in (a) surface temperature, (b) surface pressure, (c) precipitation, (d) sea surface temperature, (e) zonal surface wind (denoted as $U$-winds) and (f) meridional surface winds (denoted as $V$-winds) shown as responses to a change in aerosols by 1 optical depth unit for year 1 after the eruption. 
(a) Surface Temperature

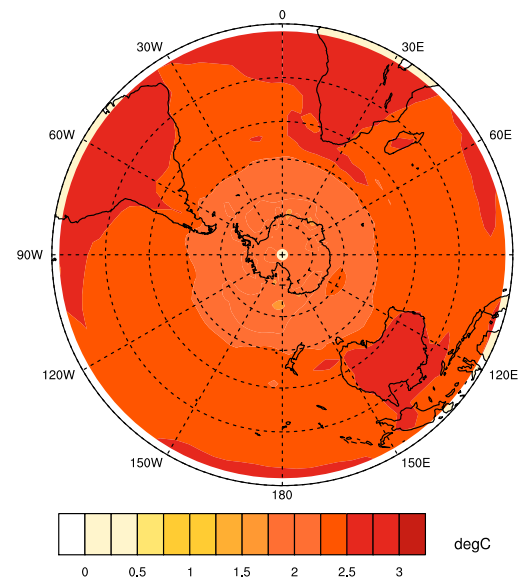

(c) Precipitation

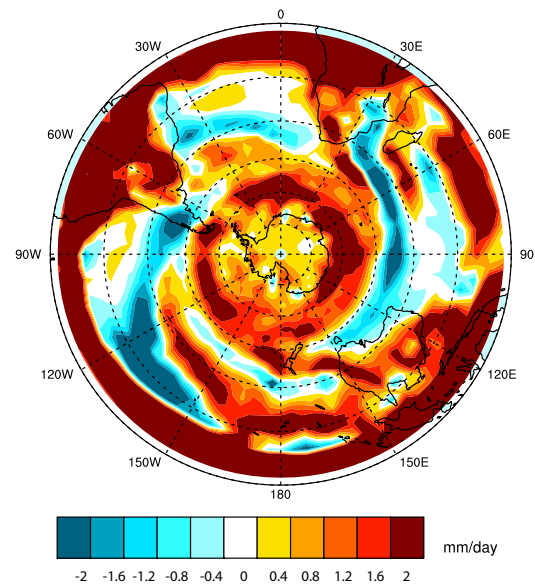

(e) Surface U-winds

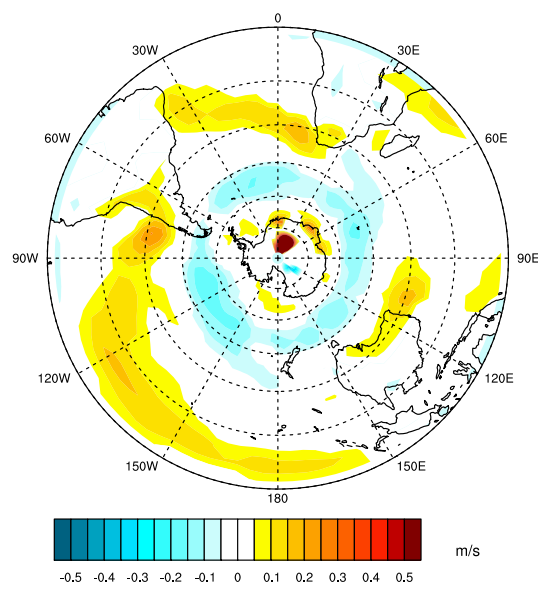

(b) Surface Pressure

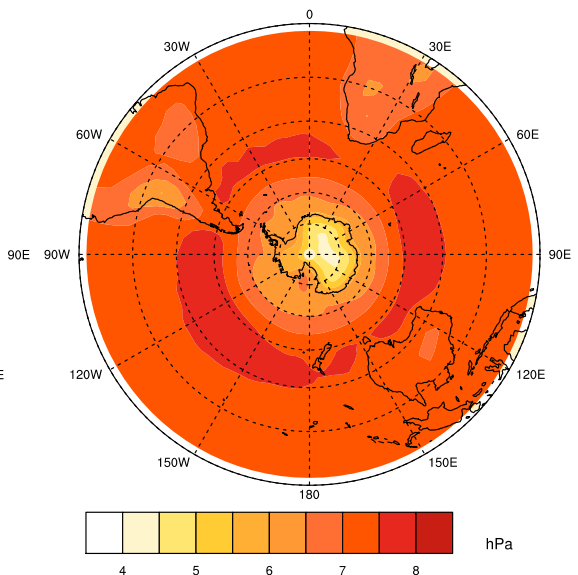

(d) Sea Surface Temperatures

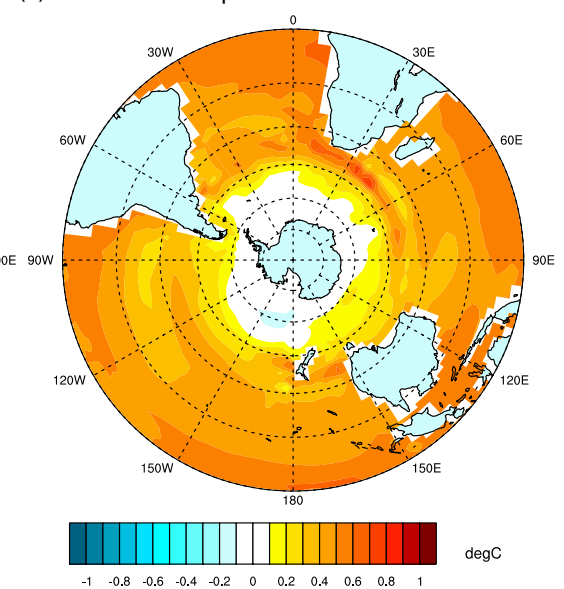

(f) Surface V-winds

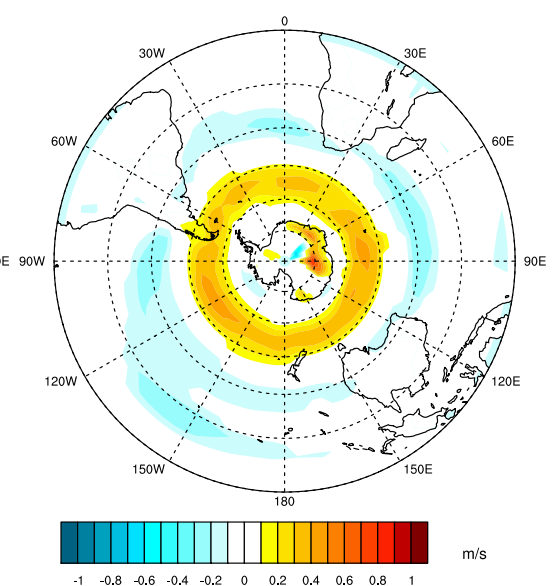

Fig. 9. Regression coefficients of summed GHG and solar forcing and (a) surface temperature, (b) surface pressure, (c) precipitation, (d) sea surface temperature, (e) zonal surface winds (denoted as $U$-winds) and (f) meridional surface winds (denoted as $V$-winds) after the impact of the volcanic eruptions was removed. For (c) to (f) only values significant at the $5 \%$ level are shaded. 
Table 2. Regional surface temperatures in the transient simulations for South America (SA1 to SA4) correlated with the Southern Annular Mode index (SAM), South Pacific Dipole index (SPD) and Zonal Wave 3 index (ZW3). For each variable and region, respectively, the highest and lowest correlation coefficients of the four ensemble members are shown.

\begin{tabular}{llll}
\hline Region & SAM & SPD & ZW3 \\
\hline SA1 & $0.180 ; 0.204^{* *}$ & $0.171 ; 0.196^{* *}$ & $0.360 ; 0.375^{* *}$ \\
SA2 & $-0.032 ;-0.025^{*}$ & $0.160 ; 0.165^{* *}$ & $0.044 ; 0.071^{* *}$ \\
SA3 & $-0.114 ;-0.093^{* *}$ & $-0.05 ;-0.031$ & $-0.094 ;-0.062^{* *}$ \\
SA4 & $-0.110 ;-0.061^{* *}$ & $-0.157 ;-0.124^{* *}$ & $0.035 ; 0.045^{* *}$ \\
\hline
\end{tabular}

* Coefficients significant at the $5 \%$ level.

** Coefficients significant at the $1 \%$ level.

supported by the significantly positive correlations with all three modes (Table 2). For SA2, advection again plays an important role and the dynamics most closely reflect a combination of SPD and ZW3; however, it is not a clear signal. The correlations appear much weaker; for SAM they lie close to zero. For both SA3 and SA4, a dipole pattern with opposite poles located in the South Pacific and the South Atlantic emerges. The correlations suggest that temperature for SA3 is influenced by SAM and SPD; for SA4, all three modes are significantly correlated with regional temperatures. However, the underlying dynamical signal indicates that advection is not sufficient to explain temperature variations in this region and other processes such as convection or local effects must play a role. The importance of variations in external forcing is discussed in the next section.

For precipitation variations a very similar picture emerges. For Patagonia the underlying dynamics reflect a combination of the SAM and the SPD; the correlations (Table 3) support this and in addition suggest a significant influence of the ZW3. Advection plays an important role in this region and changes in the westerly winds influence the amount of moisture and, thus, precipitation which reaches Patagonia. For SA2 the mechanisms are similar, and changes in the advection of moist air from the west are the main mechanism for variations in precipitation. In comparison to SA1, however, a weakening of the influence of the ZW3 is noticeable. For SA3, a tripole pattern with a positive centre located over the South Pacific and two negative poles over the South Atlantic appear. Here, the correlations point towards a weak but significant influence of SAM and ZW3; however, in this area further processes presumably play a role than simple advection such as convection, external forcing or topographical effects. For SA4, a pattern with poles of opposite signs over the South Pacific and the South Atlantic emerges similar to the one found for temperatures in this area; however, the correlations in contrast only point to a weak impact of SPD and ZW3 and again the underlying cause of the precipitation variations is not identifiable from the atmospheric dynamics.

Therefore, in the regions SA1 to SA4 never only a single mode is responsible for the regional temperature and precipitation variations. Rather, the underlying dynamics reflect a combination of modes which is especially the case for SA1 and 2. It seems as though atmospheric dynamics cannot solely explain variations in SA3 and 4.

In order to faithfully reconstruct changes in the state of an atmospheric mode, it is a prerequisite that the teleconnection patterns of the respective mode do not change over time and the mode's relationship to regional temperature and precipitation remains constant over time. In doing so, 50-yr running correlations between regional temperature and precipitation and the time series of the modes are analyzed to assess the stability of the modes. Both for temperature and precipitation, the correlations remain constant over time: neither strong shifts nor reversals in sign are found (not shown). No marked changes can be seen when reducing the time window from $50 \mathrm{yr}$ to $30 \mathrm{yr}$, therefore suggesting that the structure of the modes and the teleconnections to regional temperature and precipitation remain fairly constant over the $500 \mathrm{yr}$ analyzed. Also, the range in the correlations values between the respective ensemble members is small (Tables 2 and 3).

\subsection{Impact of the external forcing}

The external forcing appears to have a strong impact on regional climate in southern South America. For a quantitative analysis we separate the effects of the volcanic eruptions from the combined GHG and solar forcing. In a first step the impact of the volcanic eruption was determined, and in a second step it was removed from the time series of the respective variable. First, the average anomalies for year 1 , year 2 and year 3 after the volcanic event were determined against the $3 \mathrm{yr}$ mean prior to the eruption. This was done over the period from $1500 \mathrm{AD}$ to $1620 \mathrm{AD}$, because during these years the eruptions are temporally well separated and the changes in GHG and solar forcing are small. In a next step, the regression coefficients between the anomalies of the respective variable in year 1 to 3 and the strength of the eruption were determined. Then, the impact of the volcanic eruptions was removed by multiplying the regression coefficients for year 1 to 3 with the time series of the volcanic 
Table 3. Same as Table 2 but for precipitation.

\begin{tabular}{llll}
\hline Region & SAM & SPD & ZW3 \\
\hline SA1 & $-0.299 ;-0.282^{* *}$ & $0.165 ; 0.168^{* *}$ & $-0.393 ;-0.353^{* *}$ \\
SA2 & $0.056 ; 0.091^{* *}$ & $-0.214 ;-0.179^{* *}$ & $0.049 ; 0.093^{* *}$ \\
SA3 & $0.031 ; 0.061^{*}$ & $-0.106 ;-0.074$ & $-0.013 ; 0.014$ \\
SA4 & $-0.028 ; 0.004$ & $0.058 ; 0.086^{* *}$ & $0.049 ; 0.059^{* *}$ \\
\hline
\end{tabular}

eruptions and subtracting it from the time series of the respective variable. The impact of the combined GHG and solar forcing was estimated by performing a regression between the summed solar and GHG forcing and the variable of interest (e.g. temperature and precipitation).

Starting with the linear response to volcanic eruptions, we find that during the first year after a volcanic event temperatures over South America and large parts of the SH drop by an average of $2{ }^{\circ} \mathrm{C}$. The corresponding changes in sea surface temperatures lie around up to $1^{\circ} \mathrm{C}$ and are least pronounced over the Southern Ocean. For surface pressure there is a rather weak response showing similarities to the structure of SAM in the sector from $90^{\circ} \mathrm{E}$ to $120^{\circ} \mathrm{W}$. No clear signals emerge for either zonal or meridional winds; for precipitation the changes are strong but are difficult to link to dynamical changes.

An increase in the combined solar and GHG forcing in the simulations results in an average change in surface temperature of approximately $2{ }^{\circ} \mathrm{C}$ over the Southern Ocean; towards the tropics and over the large $\mathrm{SH}$ landmasses the changes become more pronounced and range up to $3^{\circ} \mathrm{C}$. The surface pressure changes appear very uniform over the entire $\mathrm{SH}$; the strongest changes occur over the Southern Ocean whereas they are weakest over Antarctica. Precipitation signals are heterogeneous over the $\mathrm{SH}$; over the tropics a general increase in precipitation can be seen, whereas in the midlatitudes an increase in the external forcing generally leads to slight decrease. Over the margins of Antarctica, in contrast, an increase is detected. Over South America a tripole pattern is found, with increases over the tropical and subtropical areas and the southern tip of South America and decreased precipitation over $30-40^{\circ} \mathrm{S}$. As for surface temperatures, an increase in external forcing levels results in warmer sea surface temperatures. The response is strongest in the tropics and weakest over the Southern Ocean due to the thermal inertia in this area. An increase in the external forcing by $1 \mathrm{~W} \mathrm{~m}^{-2}$ leads to a weakening of the zonal winds in the mid-latitudes by approximately $0.7 \mathrm{~km} \mathrm{~h}^{-1}$ - a small value in comparison to the large fluctuations taking place in this area. In the subtropics the zonal wind is increased (around $30^{\circ} \mathrm{S}$ ). At the same time a weakening of the same order of magnitude of the equatorial easterlies can be observed. A general strengthening of the northerly component of the meridional winds between $45^{\circ} \mathrm{S}$ and $60^{\circ} \mathrm{S}$ is found, which illustrates that during high forcing situations there is a reduced inflow to Antarctica. In contrast, the meridional wind component shows an increase of southerly winds in the subtropics. This leads to a convergence zone around $35^{\circ} \mathrm{S}$.

\section{Discussion}

\subsection{Atmospheric modes}

The most prominent changes occurring in the modes over the past $500 \mathrm{yr}$ in the ensemble of simulations can be seen for the SAM, whereas the SPD and the ZW3 show few notable changes throughout the simulations.

Changes in the SAM have also been observed during the last decades (Thompson and Wallace, 2000; Gong and Wang, 1999; Marshall, 2003) and have been attributed to both the ozone losses and the increase in GHG concentrations (Arblaster and Meehl, 2006), whereby the changes in the upper atmosphere were mainly driven by ozone and the trends at the surface were a result of the combined GHG and ozone forcing. The simulations used in this study neither included ozone nor aerosols as components of the external forcing. Nevertheless, the model is still able to reproduce the trends in the observations. This has also been found in several previous simulations (Kushner et al., 2001; Rauthe and Paeth, 2004) driven solely with GHGs, thus suggesting that, next to the important trends in ozone, GHGs also play a role in the recent SAM trends (Arblaster and Meehl, 2006; Cai and Cowan, 2007; Roscoe and Haigh, 2007). Indeed, the beginning of the increase in the SAM index corresponds closely to the increase in GHGs around 1850 AD.

Recently, several reconstructions of SAM variability (Jones and Widmann, 2003, 2004; Jones et al., 2009) show a stable SAM index between $1870 \mathrm{AD}$ and $1960 \mathrm{AD}$. Around 1960 AD a peak in the SAM index is found, which was followed by a sharp drop which is especially prominent in the DJF SAM reconstructions. Thereafter a significant trend in the index is visible. Neither the monthly SAM index nor the seasonal indices calculated for the transient simulations show this behavior. Furthermore, as noted earlier, the increase in the SAM index in the model began earlier than expected from 
the reconstructions. An intercomparison between the various methods used is presented in Jones et al. (2009).

No significant trends in the SPD can be seen over the course of the transient simulations. On the one hand this may be the result of the strong baroclinicity of CCSM3 (Yeager et al., 2006) preventing tropical and extratropical anomalies from propagating to the polar latitudes and masking meridional variations. A further possibility may also be given by the very regular ENSO in the model which also shows no significant shifts in variability strength and frequency throughout the course of the 500 model years. As ENSO also influences the South Pacific-to-Atlantic wave train (Kiladis and Mo, 1998), it is thus not surprising that no changes in this variability mode occur in the model.

No trends in the ZW3 show up as a result of the external forcing. This result is consistent with Raphael and Holland (2006) who found that the slightly positive trend in the NCEP/NCAR reanalysis data was presumably a result of internal variability as it could not be verified by any of the different models they used. Thus, these two modes (ZW3 and SPD) should also not lead to major changes in Southern Hemisphere climate over the past 500 model years, even though the ZW3 appears to have a much greater impact on climate in southern South America (in CTRL1990 it explains $15 \%$ of temperature and precipitation variability).

Recent work by Ding et al. (2011), however, shows that SST-anomalies in the tropical Pacific, which are not related to ENSO, influence temperatures over western Antarctica and the Antarctic Peninsula by modifying the strength of the Amundsen low through a Rossby wave train originating in the central tropical Pacific. The Amundsen low is part of the wave trains of both the SPD and the ZW3; therefore, this result suggests that, especially in the light of future changes, changes in these modes may take place even though they show a strong degree of stability against varying external forcing throughout our simulations.

The stability of the teleconnection patterns on a month-tomonth basis is another important result of this study especially in the light of reconstructing the internal variability of the climate system. Proxy archives and observational data, however, suggest that the link is not as straightforward and that changes over time may well occur, e.g. through the modification of one mode through another. For example, Gregory and Noone (2008) showed that the ENSO imprint on $\delta^{18} \mathrm{O}$ in Antarctic ice cores was modified according to the state of SAM. A further study by Richard et al. (2001) indicates that the relationship between ENSO and precipitation patterns has shown a pronounced shift during the last $50 \mathrm{yr}$ over Africa due to changes in convection over the Indian Ocean. Marshall (2007) points out a reversal in the SAM - temperature relationship over East Antarctica which occurred during the 1980s due to a change in the long-wave patterns over Antarctica. Also, the linkage between different proxy archives is hampered by dating uncertainties, reconstruction methods and regional changes as Wilson et al. (2010) demonstrate. They showed that a number of ENSO reconstructions have a similar spectral behavior that, however, the spatial and temporal consistency is not given. Again this points to the varying influence of the main modes of internal variability on remote areas. For the Northern Hemisphere Raible et al. (2006) find that proxies show notable shifts in teleconnectivity especially during the Maunder Minimum, which partly explain changes in temperature and precipitation. In contrast, their model (CCSM2.0 which is the precursor model of the one used for this study) showed much more stable teleconnections for both a perpetual CTRL1990 and a future projection. Therefore, even though the model used for this study points towards stable teleconnections, a number of proxy and observational records do not; hence, the results of this study need to be treated with caution and require further investigation.

\subsection{Regional temperature and precipitation reconstructions}

To date not many temperature and precipitation reconstructions from the mid and high latitude $\mathrm{SH}$ exist. Two recently published studies (Neukom et al., 2011, 2010) take a multi-proxy approach for reconstructing southern SouthAmerican temperature and precipitation fields and reach back to $900 \mathrm{AD}$ and $1500 \mathrm{AD}$, respectively. These reconstructions provide intriguing possibilities for comparison with the model results of this study. Their reconstruction area for both variables encompasses the land masses of southern South America south of $20^{\circ} \mathrm{S}$, thus corresponding to a compilation of the regions SA1, SA2 and the southernmost parts of SA3 and SA4. Their studies suggest major variations in southern South America temperatures during the past $500 \mathrm{yr}$ and that additionally the seasonal time series of temperature differed significantly.

The regional time series for the model ensemble simulations do not show the prominent changes that the proxy records suggest. Also, the differences between the summer and the winter season appear much less pronounced. The simulated records show very little variability on both seasonal and year-round time scales and appear to react rather to the increase in GHGs and the decreased radiative forcing during volcanic events which stands in contrast to the reconstructions.

The precipitation reconstructions (Neukom et al., 2010) again present a distinctly different picture for the winter and summer seasons; however, in comparison to the temperature fluctuations, precipitation values show much more consistent patterns. The annual precipitation reconstructions by Tonello et al. (2009) also indicate that precipitation in southern South America was highly variable during the past centuries. This strong variability, however, is not apparent in the modeled temperature records. Precipitation remains fairly stable throughout the simulations, and no prominent shifts or significant trends emerge such as can be seen in 
the proxy records, suggesting that precipitation in southern South America in CCSM3 is fairly robust against changes in external forcing. This again may be related to the small changes in strength of the westerly winds throughout the course of the simulations.

\subsection{Impact of the external forcing}

The modeled temperature changes in South America appear to relate mainly to a combination of the GHG and volcanic forcing. Unlike these findings, precipitation levels do not appear to be affected by changes in external forcing but also do not show a clear linkage to any of the variability modes. This stands in contrast to the clear linkages between the regional precipitation and modes such as SAM or ENSO (Garreaud et al., 2009) appearing in observations. One of the problems may be the resolution of the model reducing the impact of the variability modes and increasing the impact of the external forcing in the case of temperature variability. The low resolution also reduces the complexity of the topography, which is an important factor in representing regional climatic variations accurately. A further effect damping the regional climate variations may be the lacking changes in oceanic variability. The areas that were analyzed in this study are all surrounded to a large degree by large water masses and thus influenced by variability in oceanic parameters such as currents or temperatures.

It can be seen that changes in the GHG and solar forcing lead to significant changes in Southern Hemisphere climate. As expected from basic physical principles, an increase in the radiative forcing results in an increase in temperature. These are least pronounced in the Southern Ocean section due to the large heat capacity of this huge water mass. Also, as it is an area of widespread upwelling, temperature changes are masked by cold deep waters returning to the surface here. Due to the weak changes in external forcing during the first $350 \mathrm{yr}$ of the simulations (less than $0.5 \mathrm{~W} \mathrm{~m}^{-2}$ ), internal variability presumably masks the impacts of the changes in external forcing. The changes in the atmospheric dynamics show a less clear picture than the temperature changes. For the last $150 \mathrm{yr}$ the results suggest GHG and solar forcing increases lead to a pressure increase over the mid-latitudes, whereas a very slight deepening of pressure over Antarctica takes place. This pattern corresponds to the increased SAM index that can be seen for both the transient simulations and observational data (Marshall, 2003). One effect expected due to these changes in pressure would be an increase in mid-latitude westerly winds. This, however, is not found in our simulations. The changes in the westerly winds are very small in comparison to the year-round and interannual fluctuations and thus suggest that the Southern Hemisphere westerlies in the model appear fairly robust against the forcing. This corresponds to results for the Southern Annular Mode where it was noted that a strengthening and southward shift in the westerly winds can only be observed during the last years of the transient simulations. One problem in this context is presumably the low resolution of the model. The observed recent poleward shifts of the westerlies noted by e.g. Biastoch et al. (2009) take place on sub-grid scales of our model; thus, even if the model was able to correctly represent the dynamics behind the shift, it would not be able to actually show the shift. Also, it is believed that ozone is one major contributor to the strengthening of the winds; the model used for this study, however, does not incorporate ozone changes. The pattern for the meridional winds corresponds well to the changes for geopotential height. An increase in the northward component over the Southern Ocean can be seen, whereas a slight southward increase of the winds occurs over the mid-latitudes. This pattern corresponds to the mechanism noted by Hall and Visbeck (2002); however, it comes without the increase in the westerlies which has been simulated by a large range of models (Fyfe and Saenko, 2006).

\section{Conclusions}

In this study several different approaches were taken to characterize the climate change in the Southern Hemisphere midand high-latitudes, in particular over South America, over the past $500 \mathrm{yr}$ as an ensemble of simulations conducted with CCSM3 with time varying external forcing.

Firstly, changes in the main modes of variability were evaluated by estimating the patterns for the CTRL1990 simulation and then projecting them onto the transient simulations to obtain a measure of the state of the mode. No changes were found for the SPD and the ZW3 and the patterns remained robust throughout the simulations. This, however, does not exclude that changes in the future with even higher GHG levels may occur.

However, we found that a shift in the SAM occurred during the last century of the simulations. It is related to an increase in pressure over the mid-latitudes increasing the gradient between the mid- and high-latitudes. An increase in the strength of the Southern Hemisphere westerlies and a poleward shift of the wind system does not occur until the end of the 20th century. The changes in the SAM correspond to a variety of recent observation but also model simulations. It is important to note that the simulations conducted for this study did not use ozone forcing; thus, one important result is that the recently observed changes in SAM may at least in part be driven by GHG changes.

A further important result is the stability of the teleconnection patterns with regional climate in the mid latitude Southern Hemisphere over time. No significant changes in the correlations between regional temperature and precipitation and the respective modes of atmospheric variability could be seen. The stability of the teleconnections provides helpful conclusions for the proxy community as it suggests the spatial patterns of the modes remained the same over time, and thus could provide the opportunity for reliably reconstructing 
the atmospheric variability modes over time, as previously done, e.g. ENSO or SAM. However, as discussed in the previous section, these results need to be treated with care, as a stronger external forcing may well change the teleconnection patterns, and they may be biased by errors in the model.

In this model, regional temperature changes are dominated by the changes in the external forcing, i.e. the increase in the GHGs during the last century and volcanic eruptions throughout the course of the simulations. No significant trends or shifts in precipitation are found for either of the analyzed regions. The underlying dynamics of the regional temperature variations rarely point to only one single atmospheric mode; mostly, at least two modes are involved in changes of the geopotential height field at $850 \mathrm{hPa}$. For precipitation, however, the influence of the SAM on the variability can clearly be seen which is associated with the strength and position of the mid latitude storm tracks influencing the amounts of regional precipitation.

However, as noted previously, especially temperature rarely reflects only a single mode of variability, but rather a combination of modes, i.e. SAM, SPD and ZW3, as can, for example, be seen for Patagonia (SA1), thus making it hard to find distinct locations or regions which solely reflect the signal of only one mode. Hence, one important conclusion of this study is that much care needs to be taken when reconstructing Southern Hemisphere variability modes from precipitation or temperature proxies, as the inferred signals may be an overlap of several different dynamical modes.

The impact of the combined external forcing, i.e. solar and GHG forcing, after the impact of the volcanic eruptions has been removed, shows that an increase in the external forcing results in an increase of both surface and sea surface temperature, which is most pronounced over the mid and tropical latitudes, whereas the weakest changes can be seen over the Southern Ocean. Consistent with the temperature increase in the Southern Hemisphere, a decrease in sea ice concentration, especially at the margins, can be seen for most of Antarctica. No large changes in the zonal winds are detected; however, for the meridional winds a strengthening of the northerly component close to Antarctica can be observed. Furthermore, geopotential height increases with a shift in the external forcing to higher values, which at least partly explains the increase in the SAM index over this period. The changes in precipitation are very regional; however, in general, an increase in precipitation over the midlatitude continents occurs with increasing forcing.

It would be interesting to now carry out the same analyses on a whole set of models (e.g. the upcoming PMIP3 simulations) to extract robust results and to assess uncertainties of the individual models. Also, this study used the coarse resolution version of CCSM3; an increase in resolution of $1^{\circ} \times 1^{\circ}$ could lead to an improvement of the results. In addition, it would be intriguing to perform simulations which reached further into the past to see how Southern Hemisphere atmospheric variability change, e.g. throughout the Holocene, and whether teleconnection patterns remain stable under stronger external forcing and in a different model set. Of course, a further related step would be to assess the evolution of variability of the modes with increasing external forcing applying different scenarios.

Then, further emphasis should be laid on connecting the proxy records and extending the network of reconstructions. Once more records exist, it would be interesting to perform a set of simulations with data assimilation where the reconstructions serve as described by Goosse et al. (2006) to increase the currently, in comparison to the $\mathrm{NH}$, limited knowledge on climate variability in the mid- and high-latitudes of the SH.

Acknowledgements. We would like to thank D. Hofer, F. Lehner and N. Merz for the fruitful discussions and their input to this work. This work is supported by the National Centre for Competence in Research (NCCR) on Climate funded by the Swiss National Science Foundation. ERA-40 reanalysis data were provided by European Centre for Medium-Range Weather Forecasts (ECMWF, http://data.ecmwf.int/data/index.html). The CCSM3 simulations are performed on the super computing architecture of the Swiss National Supercomputing Centre (CSCS).

Edited by: M. Grosjean

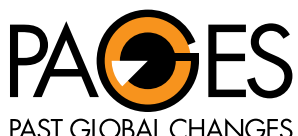

The publication of this article was sponsored by PAGES.

\section{References}

Ammann, C. M. and Naveau, P.: Statistical analysis of tropical explosive volcanism occurrences over the last 6 centuries, Geophys. Res. Lett., 30, 1210, doi:10.1029/2002GL016388, 2003.

Ammann, C. M., Joos, F., Schimel, D. S., Otto-Bliesner, B. L., and Tomas, R. A.: Solar influence on climate during the past millennium: Results from transient simulations with the NCAR Climate System Model, P. Natl. Acad. Sci., 104, 3713-3718, 2007.

Araneda, A., Torrejon, F., Aguayo, M., Torres, L., Cruces, F., Cisternas, M., and Urrutia, R.: Historical records of San Rafael glacier advances (North Patagonian Icefield): another clue to "Little Ice Age" timing in southern Chile?, Holocene, 17, 987998, 2007.

Arblaster, J. M. and Meehl, G. A.: Contributions of external forcings to Southern Annular Mode trends, J. Climate, 19, 28962905, 2006.

Biastoch, A., Boning, C. W., Schwarzkopf, F. U., and Lutjeharms, J. R. E.: Increase in Agulhas leakage due to poleward shift of Southern Hemisphere westerlies, Nature, 462, 495-498, 2009.

Blunier, T., Chappellaz, J., Schwander, J., Stauffer, B., and Raynaud, D.: Variations in atmospheric methane concentration during the Holocene, Nature, 374, 46-49, 1995. 
Cai, W. and Cowan, T.: Impacts of increasing anthropogenic aerosols on the atmospheric circulation trends of the Southern Hemisphere: An air-sea positive feedback, Geophys. Res. Lett., 34, L23709, doi:10.1029/2007GL031706, 2007.

Collins, W. D., Bitz, C. M., Blackmon, M. L., Bonan, G. B., Bretherton, C. S., Carton, J. A., Chang, P., Doney, S. C., Hack, J. J., Henderson, T. B., Kiehl, J. T., Large, W. G., McKenna, D. S., Santer, B. D., and Smith, R. D.: The Community Climate System Model Version 3 (CCSM3), J. Climate, 19, 2122-2143, 2006.

Crowley, T. J.: Causes of Climate change over the past 1000 years, Science, 289, 270-277, 2000.

Ding, Q., Steig, E. J., Battisti, D. S., and Küttel, M.: Winter warming in West Antarctica caused by central tropical Pacific warming, Nat. Geosci., 4, 398-403, 2011.

Etheridge, D. M., Steele, L. P., Langenfelds, R. L., Francey, R. J., Barnola, J.-M., and Morgan, V. I.: Natural and anthropogenic changes in atmospheric $\mathrm{CO}_{2}$ over the last 1000 years from air in Antarctic ice and firn, J. Geophys. Res., 101, 4115-4128, 1996.

Flueckiger, J., Monnin, E., Stauffer, B., Schwander, J., Stocker, T. F., Chappellaz, J., Raynaud, D., and Barnola, J.-M.: Highresolution Holocene $\mathrm{N}_{2} \mathrm{O}$ ice core record and its relationship with $\mathrm{CH}_{4}$ and $\mathrm{CO}_{2}$, Global Biogeochem. Cy., 16, 1010, doi:10.1029/2001GB001417, 2002.

Fyfe, J. C. and Saenko, O. A.: Simulated changes in the extratropical Southern Hemisphere winds and currents, Geophys. Res. Lett., 33, L06701, doi:10.1029/2005GL025332, 2006.

Garreaud, R. D., Vuille, M., Compagnucci, R., and Marengo, J.: Present-day South American climate, Palaeogeogr. Palaeocl., 281, 180-195, 2009.

Gong, D. and Wang, S.: Definition of Antarctic Oscillation index, Geophys. Res. Lett., 26, 459-462, 1999.

Gonzalez-Rouco, J. F., Fernandez-Donado, L., Raible, C. C., Barriopedro, D., Garcia-Herrera, R., Luterbacher, J. J., Swingedow, D., Servonat, J., Tett, S., Brohan, P., Zorita, E., Wagner, S., and Ammann, C.: Medieval Climate Anomaly to Little Ice Age transition as simulated by current climate models, Pages Newsletter, 19, 7-10, 2011.

Goosse, H., Renssen, H., Timmermann, A., Bradley, R., and Mann, M.: Using paleoclimate proxy-data to select optimal realisations in an ensemble of simulations of the climate of the past millennium, Clim. Dynam., 27, 165-184, 2006.

Gregory, S. and Noone, D.: Variability in the teleconnection between the El Niño Southern Oscillation and West Antarctic climate deduced from West Antarctic ice core isotope records, J. Geophys. Res., 113, D17110, doi:10.1029/2007JD009107, 2008.

Hall, A. and Visbeck, M.: Synchronous variability in the Southern Hemisphere atmosphere, sea ice, and ocean resulting from the Annular Mode, J. Climate, 15, 3043-3057, 2002.

Hofer, D., Raible, C. C., and Stocker, T. F.: Variations of the Atlantic meridional overturning circulation in control and transient simulations of the last millennium, Clim. Past, 7, 133-150, doi:10.5194/cp-7-133-2011, 2011.

Jansen, E., Overpeck, J., Briffa, K., Duplessy, J.-C., Joos, F., Masson-Delmotte, V., Olago, D., Otto-Bliesner, B., Peltier, W., Rahmstorf, S., Ramesh, R., Raynaud, D., Rind, D., Solomina, O., Villalba, R., and Zhang, D.: Palaeoclimate, in: Climate Change 2007: The physical Science Basis. Contribution of Working Group I to the Fourth Assessment Report of the Inter- governmental Panel on Climate Change, Cambridge University Press, Cambridge, United Kingdom and New York, NY, USA, 2007.

Jones, J. M. and Widmann, M.: Instrument- and tree-ring-based estimates of the Antarctic Oscillation, J. Climate, 16, 3511-3524, 2003.

Jones, J. M. and Widmann, M.: Atmospheric science: Early peak in Antarctic Oscillation index, Nature, 432, 290-291, 2004.

Jones, P. D. and Mann, M. E.: Climate over past millennia, Rev. Geophys., 42, RG2002, doi:10.1029/2003RG000143, 2004.

Jones, P. D., Briffa, K., Osborn, T., Lough, J., van Ommen, T., Vinther, B., Luterbacher, J., Wahl, E., Zwiers, F., Mann, M. E., Schmidt, G., Ammann, C., Buckley, B., Cobb, K., Esper, J., Goosse, H., Graham, N., Jansen, E., Kiefer, T., Kull, C., Küttel, M., Mosley-Thompson, E., Overpeck, J., Riedwyl, N., Schulz, M., Tudhope, A., Villalba, R., Wanner, H., Wolff, E., and Xoplaki, E.: High-resolution palaeoclimatology of the last millennium: a review of current status and future prospects, Holocene, 19, 3-49, 2009.

Kidson, J. K.: Modes of Southern Hemisphere Low-Frequency Variability Obtained from NCEP-NCAR Reanalyses, J. Climate, 12, 2808-2830, 1999.

Kiladis, G. N. and Mo, K. C.: Meteorology of the Southern Hemisphere, in: Interannual and intraseasonal variability in the Southern Hemisphere, edited by: Karoly, D. J. and Vincent, D. G., 307-336, 1998

Kushner, P., Held, I., and Delworth, T.: Southern Hemisphere atmospheric circulation response to global warming., J. Climate, 14, 2238-2249, 2001.

Lean, J., Beer, J., and Bradley, R.: Reconstruction of solar irradiance since 1610: Implications for climate change, Geophys. Res. Lett., 22, 3195-3198, 1995.

Lefebvre, W., Goosse, H., Timmermann, R., and Fichefet, T.: Influence of the Southern Annular Mode on the sea ice-ocean system, J. Geophys. Res., 109, C09005, doi:10.1029/2004JC002403, 2004.

Luterbacher, J., Neukom, R., Gonzalez-Rouco, F. J., FernandezDonado, L., Raible, C., and Zorita, E.: Reconstructed and simulated Medieval Climate Anomaly in Southern South America, Pages Newsletter, 19, 20-21, 2011.

Marshall, G. J.: Trends in the Southern Annular Mode from observations and reanalyses, J. Climate, 16, 4134-4143, 2003.

Marshall, G. J.: Half-century seasonal relationships between the Southern Annular mode and Antarctic temperatures, Int. J. Climatol., 27, 373-383, 2007.

Masiokas, M., Luckman, B., Villalba, R., Delgado, S., Skvarca, P., and Ripalta, A.: Little Ice Age fluctuations of small glaciers in the Monte Fitz Roy and Lago del Desierto areas, south Patagonian Andes, Argentina, Palaeogeogr. Palaeocl., 281, 351-362, 2009.

Mo, K. C.: Relationships between low-frequency variability in the Southern Hemisphere and sea surface temperature anomalies, J. Climate, 13, 3599-3610, 2000.

Neukom, R., Luterbacher, J., Villalba, R., Küttel, M., Frank, D., Jones, P. D., Grosjean, M., Esper, J., Lopez, L., and Wanner, H.: Multi-centennial summer and winter precipitation variability in southern South America, Geophys. Res. Lett., 37, L14708, doi:10.1029/2010GL043680, 2010.

Neukom, R., Luterbacher, J., Villalba, R., Küttel, M., Frank, D., 
Jones, P., Grosjean, M., Wanner, H., Aravena, J.-C., Black, D., Christie, D., D’Arrigo, R., Lara, A., Morales, M., Soliz-Gamboa, C., Srur, A., Urrutia, R., and von Gunten, L.: Multiproxy summer and winter surface air temperature field reconstructions for southern South America covering the past centuries, Clim. Dynam., 37, 1-17, 2011.

Parry, M., Canziani, O., Palutikof, J., van der Linden, P., and Hanson, C.: Contribution of Working Group II to the Fourth Assessment Report of the Intergovernmental Panel on Climate Change, Cambridge University Press, Cambridge, United Kingdom and New York, NY, USA, 2007.

Raible, C. C., Casty, C., Luterbacher, J., Pauling, A., Esper, J., Frank, D., Büntgen, U., Roesch, A., Tschuck, P., Wild, M., Vidale, P.-L., Schär, C., and Wanner, H.: Climate variabilityobservations, reconstructions, and model simulations for the Atlantic-European and Alpine Region from 1500-2100 AD, Climatic Change, 79, 9-29, 2006.

Raphael, M. N.: A zonal wave 3 index for the Southern Hemisphere, Geophys. Res. Lett., 31, L23212, doi:10.1029/2004GL020365, 2004.

Raphael, M. N. and Holland, M.: Twentieth century simulation of the Southern Hemisphere climate in coupled models. Part 1: Large scale circulation variability, Clim. Dynam., 26, 217-228, 2006.

Rauthe, M. and Paeth, H.: Relative importance of Northern Hemisphere circulation modes in predicting regional climate change, J. Climate, 17, 4180-4189, 2004.

Richard, Y., Fauchereau, N., Poccard, I., Rouault, M., and Trzaska, S.: 20th century droughts in southern Africa: Spatial and temporal variability, teleconnections with oceanic and atmospheric conditions, Int. J. Climatol., 21, 873-885, 2001.

Roscoe, H. K. and Haigh, J. D.: Influences of ozone depletion, the solar cycle and the QBO on the Southern Annular Mode, Q. J. Roy. Meteor. Soc., 133, 1855-1864, 2007.

Thompson, D. W. J. and Wallace, J. M.: Annular Modes in the Extratropical circulation. Part I: Month-to-month variability, J. Climate, 13, 1000-1016, 2000.

Tonello, M. S., Mancini, M. V., and Seppä, H.: Quantitative reconstruction of Holocene precipitation changes in southern Patagonia, Quaternary Res., 72, 410-420, 2009.
Uppala, S. M., Kållberg, P. W., Simmons, A. J., Andrae, U., Bechtold, V. D. C., Fiorino, M., Gibson, J. K., Haseler, J., Hernandez, A., Kelly, G. A., Li, X., Onogi, K., Saarinen, S., Sokka, N., Allan, R. P., Andersson, E., Arpe, K., Balmaseda, M. A., Beljaars, A. C. M., Berg, L. V. D., Bidlot, J., Bormann, N., Caires, S., Chevallier, F., Dethof, A., Dragosavac, M., Fisher, M., Fuentes, M., Hagemann, S., Hólm, E., Hoskins, B. J., Isaksen, L., Janssen, P. A. E. M., Jenne, R., Mcnally, A. P., Mahfouf, J.-F., Morcrette, J.-J., Rayner, N. A., Saunders, R. W., Simon, P., Sterl, A., Trenberth, K. E., Untch, A., Vasiljevic, D., Viterbo, P., and Woollen, J.: The ERA-40 Re-Analysis, Q. J. Roy. Meteor. Soc., 131, 2961-3012, 2005.

Villalba, R.: Tree-ring and glacial evidence for the medieval warm epoch and the little ice age in southern South America, Climatic Change, 26, 183-197, 1994.

Villalba, R., Grosjean, M., and Kiefer, T.: Long-term multiproxy climate reconstructions and dynamics in South America (LOTRED-SA): State of the art and perspectives, Palaeogeogr. Palaeocl., 281, 175-179, 2009.

von Gunten, L., Grosjean, M., Rein, B., Urrutia, R., and Appleby, P.: A quantitative high-resolution summer temperature reconstruction based on sedimentary pigments from Laguna Aculeo, central Chile, back to AD 850, Holocene, 19, 873-881, 2009.

Wilson, R., Cook, E., D’Arrigo, R., Riedwyl, N., Evans, M. N., Tudhope, A., and Allan, R.: Reconstructing ENSO: the influence of method, proxy data, climate forcing and teleconnections, J. Quaternary Sci., 25, 62-78, 2010.

Yeager, S. G., Shields, C. A., Large, W. G., and Hack, J. J.: The low-resolution CCSM3, J. Climate, 19, 2545-2566, 2006.

Yoshimori, M., Stocker, T. F., Raible, C. C., and Renold, M.: Externally-forced and internal varibility in ensemble climate simulations of the Maunder Minimum, J. Climate, 18, 42534270, 2005.

Yoshimori, M., Raible, C. C., Stocker, T. F., and Renold, M.: Simulated decadal oscillations of the Atlantic meridional overturning circulation in a cold climate state, Clim. Dynam., 34, 101-121, 2010.

Yuan, X. and Li, C.: Climate modes in southern high latitudes and their impacts on Antarctic sea ice, J. Geophys. Res.-Oceans, 113, C06S91, doi:10.1029/2006JC004067, 2008. 